\title{
Compostos nitrogenados e carboidratos em sorgo submetido à salinidade e combinações de nitrato e amônio ${ }^{1}$
}

\author{
Nitrogenous compounds and carbohydrates in sorghum subjected to salinity and \\ combinations of nitrate and ammonium
}

\author{
Ana Karla Moreira Lobo², Marcio de Oliveira Martins², Milton Costa Lima Neto², Aurenívia Bonifácio² e \\ Joaquim Albenísio Gomes da Silveira ${ }^{3 *}$
}

\begin{abstract}
Resumo - O objetivo do trabalho foi avaliar os efeitos de combinações de nitrato e amônio no meio, na acumulação de compostos nitrogenados e carboidratos, na presença e ausência de salinidade em plantas de sorgo. Sementes do genótipo CSF 20 foram cultivadas em casa de vegetação, em solução nutritiva com três concentrações de nitrato e amônio $\left(100 \% \mathrm{NO}_{3}^{-:}: 0 \%\right.$ $\mathrm{NH}_{4}^{+}, 75 \% \mathrm{NO}_{3}^{-}: 25 \% \mathrm{NH}_{4}^{+}$e $\left.0 \% \mathrm{NO}_{3}^{-}: 100 \% \mathrm{NH}_{4}^{+}\right)$, na presença e ausência de salinidade. A salinidade reduziu a concentração de nitrato nas folhas e colmo, nos tratamentos 100:0 e 75:25. O amônio acumulou-se mais nas plantas com $\mathrm{NaCl}$, nas folhas e colmo. Os teores de aminoácidos livres totais nas folhas não se alteraram, mas, no colmo, aumentaram na presença de sal e aumento do amônio. A concentração de prolina livre nas folhas e colmo elevou-se nas plantas sob salinidade. O conteúdo de nitrogênio total foi maior nas folhas, entretanto não houve grandes alterações com a presença do sal. A concentração de carboidratos solúveis totais foi maior nas plantas tratadas com sal, exceto no colmo 0:100. Nas folhas, o teor de sacarose foi reduzido na presença do $\mathrm{NaCl}$ e aumento de amônio, enquanto, no colmo, foi maior no tratamento 75:25 com $\mathrm{NaCl}$. O teor de amido não sofreu alterações com as diferentes combinações nas formas de $\mathrm{N}$ e salinidade. Conclui-se que combinações de $\mathrm{NO}_{3}^{-}$ e $\mathrm{NH}_{4}{ }^{+}$no meio afetam a acumulação de compostos nitrogenados e carboidratos em folhas e colmo, com presença ou ausência de salinidade, em plantas de sorgo forrageiro.
\end{abstract}

Palavras-chave - Sorghum bicolor. Nitrogênio. Estresse salino.

\begin{abstract}
The objective of this study was to evaluate the effects of combinations of nitrate and ammonium in the medium, on the accumulation of nitrogen compounds and carbohydrates, in the presence and absence of salinity in sorghum plants. CSF 20 genotype sorghum seeds, were grown in the greenhouse and supplied with a nutritive solution at three different concentrations of nitrate and ammonium $\left(100 \% \mathrm{NO}_{3}^{-}: 0 \% \mathrm{NH}_{4}^{+}, 75 \% \mathrm{NO}_{3}^{-}: 25 \% \mathrm{NH}_{4}^{+}\right.$e $\left.0 \% \mathrm{NO}_{3}^{-}: 100 \% \mathrm{NH}_{4}^{+}\right)$both in the presence and absence of $\mathrm{NaCl}$. Salinity reduced the nitrate concentration in both leaves and stalks in treatments at 100:0 and 75:25. The accumulation of ammonium was higher in those plants, in both leaves and stalk, in the presence of $\mathrm{NaCl}$. The levels of free amino acids in the leaves showed no change, whereas those in the stalk increased in the presence of salt and with the increase of ammonium. The concentration of free proline in both leaves and stalk was higher in plants under salinity. The total nitrogen content was higher in the leaves without, however, showing much change in the presence of salt. The concentration of total soluble carbohydrates was higher in those plants treated with salt, except in the stalk 0:100. Sucrose levels in the leaves were lower in the presence of $\mathrm{NaCl}$ and the increase in ammonium, while they were higher in the stalk at 75:25 $\mathrm{NaCl}$. The starch content did not alter much with the different levels of nitrogen and salinity. It is concluded that $\mathrm{NO}_{3}^{-}$and $\mathrm{NH}_{4}^{+}$combinations in the medium affect the accumulation of nitrogen compounds and carbohydrates in the leaves and stalks of sorghum plants, both in the presence and absence of salinity.
\end{abstract}

Key words - Sorghum bicolor. Nitrogen. Salt stress.

\footnotetext{
* Autor para correspondência

'Recebido para publicação em 31/08/2010; aprovado em 31/01/2011

Trabalho submetido e selecionado no primeiro Simpósio Brasileiro de Salinidade realizado de 12-15/10/2010 em Fortaleza, Ceará, Brasil; Pesquisa financiada pelo Conselho Nacional de Desenvolvimento Científico e Tecnológico - CNPq

${ }^{2}$ Programa de Pós-Graduação em Bioquímica, Centro de Ciências, Universidade Federal do Ceará, Fortaleza-CE, Brasil, karlamlobo@gmail.com, momartins@yahoo.com.br, miltoncostalima@hotmail.com, aureniviablima@hotmail.com

${ }^{3}$ Departamento Bioquímica e Biologia Molecular, Centro de Ciências/UFC, Caixa Postal 6.004, Fortaleza-CE, Brasil, 60.455 970, silveira@ufc.br
} 


\section{Introdução}

A salinização do solo é um dos principais fatores abióticos que limita a produtividade agrícola, afetando principalmente regiões áridas e semi-áridas do mundo. A maioria das espécies agricultáveis é sensível à salinidade causada pela elevada concentração de sais no solo. Este problema torna-se mais preocupante haja vista que as áreas afetadas já chegam a 800 milhões de hectares no mundo, tanto em áreas irrigadas como não irrigadas. Após a exposição dos vegetais sensíveis à salinidade a concentrações superiores a $40 \mathrm{mM}$ de $\mathrm{NaCl}$ (CE a partir de $3 \mathrm{dS} \mathrm{m}^{-1}$ ), ocorre redução na taxa de crescimento da parte aérea, principalmente devido a redução da absorção de água (MUNNS; TESTER, 2008).

As altas concentrações de sais no solo, além de reduzir o potencial hídrico, podem provocar efeitos tóxicos nas plantas, causando distúrbios funcionais e perturbações no metabolismo (DEBOUBA et al., 2006). A redução do potencial osmótico no solo, provocada pelo estresse salino, dificulta a absorção de água pela planta que, em resposta, promove uma série de modificações bioquímicas, acarretando maior produção de solutos compatíveis (como aminoácidos, principalmente prolina) na célula, os quais reduzirão o potencial hídrico do vegetal, sem danificar os compartimentos subcelulares (TAIZ; ZEIGER, 2008). Sob tais condições, ocorrem mudanças na capacidade da planta em absorver, transportar e assimilar os íons necessários ao seu crescimento, principalmente o nitrogênio (MELONI et al., 2004).

$\mathrm{O}$ nitrogênio é o nutriente mineral requerido em maior quantidade pelas plantas (ZHAO et al., 2005), sendo absorvido preferencialmente sob a forma inorgânica - nitrato $\left(\mathrm{NO}_{3}^{-}\right)$e/ou amônio $\left(\mathrm{NH}_{4}^{+}\right)$. A interação entre as fontes de nitrogênio (nítrica e amoniacal) nas plantas possui efeitos diferenciados no crescimento, na qualidade vegetal, na produção de biomassa e na reprodução (LANE; BASSIRIRAD, 2002). O amônio poderia ser uma fonte preferencial de nitrogênio, pois sua absorção requer menos energia do que o nitrato (ZHOU et al., 2011). Porém poucas espécies apresentam melhor desempenho quando crescidas apenas com $\mathrm{NH}_{4}^{+}$como fonte de nitrogênio (BRITTO et al., 2001). Embora existam muitas hipóteses de que o crescimento e rendimento de plantas sejam favorecidos pela mistura de fontes de nitrogênio no meio, os mecanismos envolvidos nestes efeitos ainda não estão completamente elucidados (KRONZUCKER et al., 1999).

Dessa forma, o objetivo do presente trabalho foi avaliar os efeitos das combinações das formas disponíveis de nitrogênio para a planta (nitrato e amônio) e da salinidade na concentração de compostos que contêm nitrogênio e carboidratos em plantas jovens de sorgo forrageiro.

\section{Material e métodos}

Foram utilizadas para esse experimento sementes de sorgo forrageiro [Sorghum bicolor (L.) Moench], genótipo CSF 20, cedidas pelo Banco de Germoplasma da Empresa Pernambucana de Pesquisa Agropecuária (IPA). As sementes foram mergulhadas em solução de hipoclorito de sódio $(\mathrm{NaClO}) 2 \%$, por 10 minutos e, após lavagens com água destilada, foram embebidas em água destilada por 20 minutos. Em seguida, 50 sementes foram distribuídas em folhas de papel Germitest ${ }^{\circledR}$ umedecidas com solução de sulfato de cálcio $\left(\mathrm{CaSO}_{4}\right)$ 0,1 mM. As sementes ficaram mantidas em condições controladas (irradiância fotossinteticamente ativa de $240 \mu \mathrm{mol} \mathrm{m} \mathrm{m}^{-2} \mathrm{~s}^{-1}$; fotoperíodo de $12 \mathrm{~h} ; 27 \pm 2{ }^{\circ} \mathrm{C}$ ) por cinco dias para a germinação.

Ao final do período de germinação, as plântulas foram transferidas para casa de vegetação e transplantadas em vasos com capacidade de $1 \mathrm{~L}$, com duas plantas por vaso, contendo solução nutritiva de Hoagland modificada, diluída 4 vezes, com pH 6,0. Sete dias após o transplantio (DAT), foram iniciados três tratamentos de acordo com o suprimento de nitrogênio, cada um com 8 repetições. O primeiro tratamento foi mantido com uma solução contendo nitrato como única fonte de nitrogênio (100:0), outro com suprimento de nitrogênio semelhante à solução recomendada, contendo $75 \%$ de nitrato e $25 \%$ de amônio $(75: 25)$ e um terceiro tratamento contendo amônio como única fonte de nitrogênio (0:100). A concentração final de nitrogênio foi $5 \mathrm{mM}$ em todas as soluções, essa concentração foi utilizada para padronização dos tratamentos e é suficiente para o desenvolvimento inicial da planta.

Após sete dias foram acrescentados $100 \mathrm{mM}$ de $\mathrm{NaCl}$ na metade das repetições (quatro plantas) de cada tratamento de nitrogênio de maneira fracionada $(50 \mathrm{mM}$ no primeiro dia e mais $50 \mathrm{mM}$ no segundo dia). Dessa forma, o delineamento experimental foi um esquema fatorial $3 \times 2$, sendo três tratamentos de suprimento de nitrogênio $(100: 0 ; 75: 25$ e 0:100) e dois tratamentos de estresse salino $(-\mathrm{NaCl},+\mathrm{NaCl} 100 \mathrm{mM})$, com quatro repetições em cada tratamento. O período experimental com as plantas expostas aos dois fatores foi de 10 dias.

Ao final do período experimental, as plantas foram divididas em folhas, colmo e raízes. Metade do material foi tratado com nitrogênio líquido e armazenado em freezer $80{ }^{\circ} \mathrm{C}$ e a outra metade foi transferida para estufa com circulação forçada de ar a $55^{\circ} \mathrm{C}$ até atingir peso constante. Posteriormente o material seco foi pesado para a obtenção da massa seca (MS).

O material seco em estufa (folhas e colmo) foi macerado, pesado (100 mg) e colocado em tubos de ensaio 
onde foram adicionados $15 \mathrm{~mL}$ de água destilada. Os tubos foram transferidos para banho-maria a $95^{\circ} \mathrm{C}$, por $1 \mathrm{~h}$. Após esse período, a solução foi filtrada para obtenção de um extrato, onde foram realizadas as determinações de solutos inorgânicos. A determinação de nitrato $\left(\mathrm{NO}_{3}^{-}\right)$ no tecido foi realizada de acordo com o método do ácido salicílico (CATALDO et al., 1975). O amônio $\left(\mathrm{NH}_{4}^{+}\right)$no tecido foi determinado pelo método fenolato-hipoclorito (WEATHERBURN, 1967).

O conteúdo de nitrogênio total foi medido de acordo com Baethgen e Alley (1989). Para a extração, o material liofilizado foi digerido com ácido sulfúrico concentrado em bloco digestor e, posteriormente, o nitrogênio no material mineralizado foi quantificado como descrito a seguir. Foram adicionados em tubos de ensaio $0,1 \mathrm{~mL}$ do mineralizado, $0,9 \mathrm{~mL}$ do diluente (catalisador e ácido sulfúrico), $5,5 \mathrm{~mL}$ da solução I (fosfato de sódio dibásico 2,68\%, tartarato de sódio e potássio $5 \%$ e hidróxido de sódio $4 \%$ ), $4 \mathrm{~mL}$ da solução II (salicilato de sódio 15\% e nitroprussiato de sódio $0,03 \%$ ) e $2 \mathrm{~mL}$ da solução III (hipoclorito de sódio 5,25\%). Os tubos ficaram em banho-maria a $37{ }^{\circ} \mathrm{C}$, por $15 \mathrm{~min}$, depois foram feitas as leituras em espectrofotômetro a $650 \mathrm{~nm}$.

O material congelado (folhas e colmo) foi liofilizado, macerado, pesado $(50 \mathrm{mg})$ e transferido para tubos de ensaio onde foram adicionados $5 \mathrm{~mL}$ de água destilada. Os tubos foram colocados em banhomaria a $95{ }^{\circ} \mathrm{C}$, por $1 \mathrm{~h}$. Posteriormente, a solução foi filtrada para obtenção de um extrato, onde foram realizadas as determinações dos solutos orgânicos. As determinações de aminoácidos solúveis totais, prolina livre e carboidratos solúveis totais foram realizadas de acordo com metodologias de Yemm e Cocking (1955), Bates (1973) e Dubois et al. (1956), respectivamente. $\mathrm{O}$ amido foi extraído do material liofilizado de acordo com McCready et al. (1950), utilizando $\mathrm{HClO}_{4} 30 \%$. Após a extração o açúcar foi quantificado de acordo com Dubois et al. (1956).

O conteúdo de sacarose foi mensurado de acordo com Van Handel (1968). Para a extração, $50 \mathrm{mg}$ do material liofilizado e 1,5 mL de solução MCW (solução de metanol, clorofórmio e água 12:5:3 v/v) foram colocados em eppendorfs e ficaram sob agitação a $25^{\circ} \mathrm{C}$, por $30 \mathrm{~min}$. O material homogeneizado foi centrifugado a $10.000 \mathrm{~g}$, por $10 \mathrm{~min}$ e depois o sobrenadante foi coletado. O resíduo foi extraído pela segunda vez nas mesmas condições anteriores, seguido de centrifugação e coleta do sobrenadante. Os sobrenadantes foram então reunidos para a obtenção do extrato total. $\mathrm{Na}$ segunda parte do método foram adicionados em tubos de ensaio $2 \mathrm{~mL}$ do extrato, $0,5 \mathrm{~mL}$ de clorofórmio e $0,75 \mathrm{~mL}$ de água. Os tubos foram centrifugados a
$2.000 \mathrm{~g}$, por $10 \mathrm{~min}$, para a separação da fase aquosa. Em seguida, a fração aquosa metanólica foi coletada e transferida para banho-maria a $35{ }^{\circ} \mathrm{C}$, por $30 \mathrm{~min}$, para a evaporação do clorofórmio residual. A partir da fase aquosa foi realizada a dosagem da sacarose. Em tubos de ensaio foram adicionados $0,1 \mathrm{~mL}$ da fração aquosa e $0,1 \mathrm{~mL}$ de $\mathrm{KOH} 30 \%$ e aquecidos em banhomaria a $100{ }^{\circ} \mathrm{C}$, por $10 \mathrm{~min}$. Após o resfriamento foram adicionados aos tubos $3 \mathrm{~mL}$ de antrona (antrona 0,2\% em ácido sulfúrico), e os tubos posto em banho-maria a $40{ }^{\circ} \mathrm{C}$, por $20 \mathrm{~min}$. Após esse período, foram feitas as leituras em espectrofotômetro a $620 \mathrm{~nm}$.

Os dados foram analisados segundo análise de variância (ANOVA) e as médias comparadas pelo teste de Tukey ao nível de 5\% de significância.

\section{Resultados e discussão}

Analisando o conteúdo de nitrato no tecido, observa-se que o colmo é um órgão de reserva importante para acumulação desse íon e posterior utilização nas folhas. Nos tratamentos 100:0 e 75:25, sem adição de $\mathrm{NaCl}$, o nitrato nas folhas representou apenas $45 \%$ e $20 \%$ do nitrato armazenado no colmo, respectivamente. No entanto, no tratamento 0:100 e $\mathrm{NaCl}$, ocorreu o contrário, houve $32 \%$ mais nitrato nas folhas do que no colmo. A salinidade aplicada reduziu a concentração de nitrato tanto nas folhas como no colmo em todos os tratamentos, exceto o que contêm apenas amônio na solução, onde não houve diferença significativa entre os tratamentos $-\mathrm{NaCl}$ e $+\mathrm{NaCl}$ (FIG. 1A, 1B). Em todos os tratamentos de suprimento de nitrogênio e de salinidade, foi encontrado maior conteúdo de amônio no colmo. A maior diferença foi encontrada no tratamento 0:100 e - $\mathrm{NaCl}$, onde a concentração de amônio na folha representou apenas $7 \%$ da concentração encontrada no colmo. A salinidade favoreceu o acúmulo deste íon tanto nas folhas como no colmo. Nas folhas, a adição de $\mathrm{NaCl}$ fez com que a concentração aumentasse $241 \%, 400 \%$ e $494 \%$ nos tratamentos 100:0, 75:25 e 0:100, respectivamente. No colmo, a salinidade aplicada elevou a concentração de amônio em $81 \%, 96 \%$ e $35 \%$ nos tratamentos 100:0, 75:25 e 0:100, respectivamente (FIG. 1C, 1D). Houve interação significativa entre o estresse salino e o suprimento de nitrogênio na concentração de nitrato nas folhas e colmo e na concentração de amônio no colmo, mas essa interação não ocorreu na concentração de amônio nas folhas $(\mathrm{P}<0,05)$.

A redução da concentração de nitrato nas plantas tratadas com $\mathrm{NaCl}$ pode ser atribuída à competição dos íons $\mathrm{Cl}^{-}$pelos transportadores de $\mathrm{NO}_{3}^{-}$(OGAWA et al., 2000) 


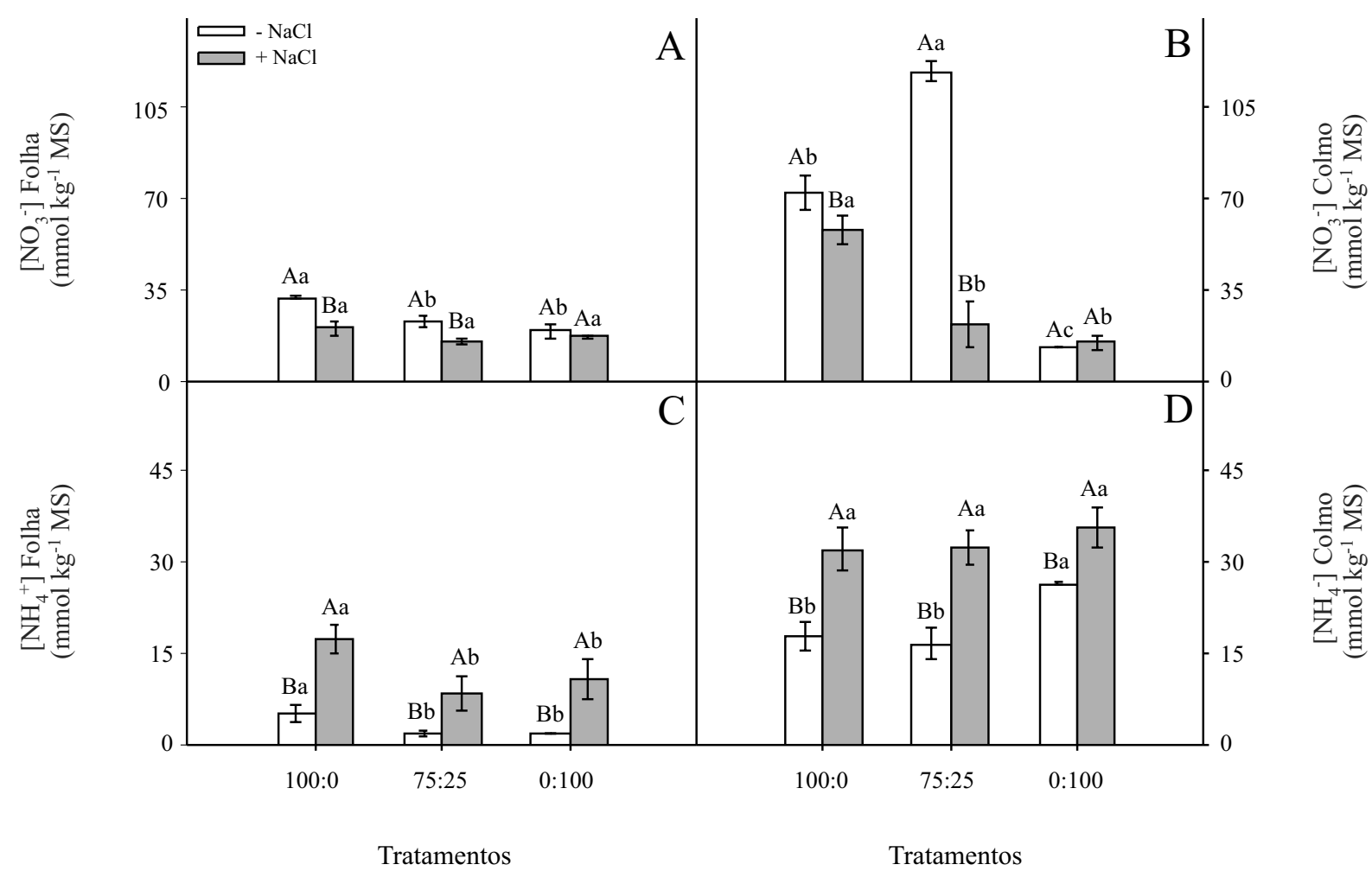

Figura 1 - Concentração de nitrato e amônio nas folhas (A e C) e colmo (B e D) de plantas de sorgo submetidas a diferentes formas de nitrogênio e à salinidade. Letras maiúsculas iguais indicam que não houve diferença significativa entre os tratamentos - $\mathrm{NaCl}$ e $+\mathrm{NaCl}$ e letras minúsculas iguais indicam que não houve diferença significativa entre os tratamentos de suplemento de nitrogênio $(100: 0,75: 25$ e 0:100) $(\mathrm{P}<0,05)$

e/ou inativação dos transportadores de $\mathrm{NO}_{3}^{-}$pelos efeitos tóxicos de íons (LIN et al., 2002). A salinidade também promove a ruptura da membrana radicular e isto inibe a absorção de $\mathrm{NO}_{3}^{-}$(PARIDA; DAS, 2004). O estresse salino afeta as enzimas que assimilam o $\mathrm{NH}_{4}^{+}$. Isto resulta em um maior acúmulo deste íon nos tecidos (ZHOU et al., 2004), além do acúmulo oriundo da degradação de proteínas resultantes do estresse aplicado (LIN et al., 2002).

Os teores de aminoácidos livres totais nas folhas não variaram entre os tratamentos de suprimento de nitrogênio nem nos tratamentos $-\mathrm{NaCl}$ e $+\mathrm{NaCl}$ (FIG. 2A). Os valores encontrados variaram entre 267 e $176 \mathrm{mmol} \mathrm{kg}{ }^{-1} \mathrm{MS}$ nas plantas do tratamento 100:0 e - $\mathrm{NaCl}$ e nas plantas 75:25 e - $\mathrm{NaCl}$, respectivamente. No entanto, o colmo acumulou mais aminoácidos livres totais quando as plantas foram submetidas à salinidade. Comparando as plantas dos tratamentos $-\mathrm{NaCl}$ e $+\mathrm{NaCl}$, observamos aumento no conteúdo de aminoácidos da ordem de $254 \%$, 326\% e $166 \%$ nos tratamentos 100:0; 75:25 e 0:100, respectivamente (FIG. 2B).
A concentração de prolina livre nas folhas foi mais elevada nas plantas sob salinidade, onde observamos elevações de $69 ; 158$ e 82\% nos tratamentos 100:0; 75:25 e 0:100, respectivamente (FIG. 2C). Entretanto, o colmo mostrou comportamento diferenciado. Nas plantas não submetidas à salinidade, dos tratamentos 100:0 e 75:25, observa-se menos prolina acumulada no colmo do que na folha ( 83 e $33 \%$, respectivamente), mas no tratamento 0:100, onde o suplemento de nitrogênio é apenas a partir de amônio, houve aumento de $168 \%$ na quantidade de prolina no colmo em relação as folhas do mesmo tratamento. Analisando somente o colmo, observamos que, quando sob salinidade, esse órgão mostra-se acumulador, com incrementos de 40; 13 e 38 vezes mais prolina no colmo das plantas submetidas à salinidade quando comparadas às plantas sem $\mathrm{NaCl}$ dos tratamentos 100:0; 75:25 e 0:100, respectivamente (FIG. 2D).

A quantidade de nitrogênio total por unidade de massa seca mostrou pequenas variações entre os tratamentos. As plantas do tratamento 100:0, sem adição 
de $\mathrm{NaCl}$, foram as que tiveram maior concentração de N-total nas folhas, reduzindo $29,6 \%$ e $35 \%$ para os tratamentos 75:25 e 0:100, respectivamente. Entre os tratamentos com adição de $\mathrm{NaCl}$, não houve diferença significativa. No colmo, houve menor concentração de nitrogênio total em relação à folha, com redução de aproximadamente $50 \%$. O tratamento que teve menor concentração de N-total foi aquele que teve o amônio como única fonte de nitrogênio $(0: 100)$. Não foram observadas diferenças significativas entre as plantas - $\mathrm{NaCl}$ e $+\mathrm{NaCl}$ (FIG. 2E; 2F). Nas concentrações de aminoácidos solúveis totais, prolina livre e nitrogênio total, as interações entre os tratamentos de suprimento de nitrogênio e estresse salino foram significativas apenas nas folhas.

Trabalhando com uma espécie híbrida, Populus $x$ canescens, crescidas com nitrato ou amônio, na

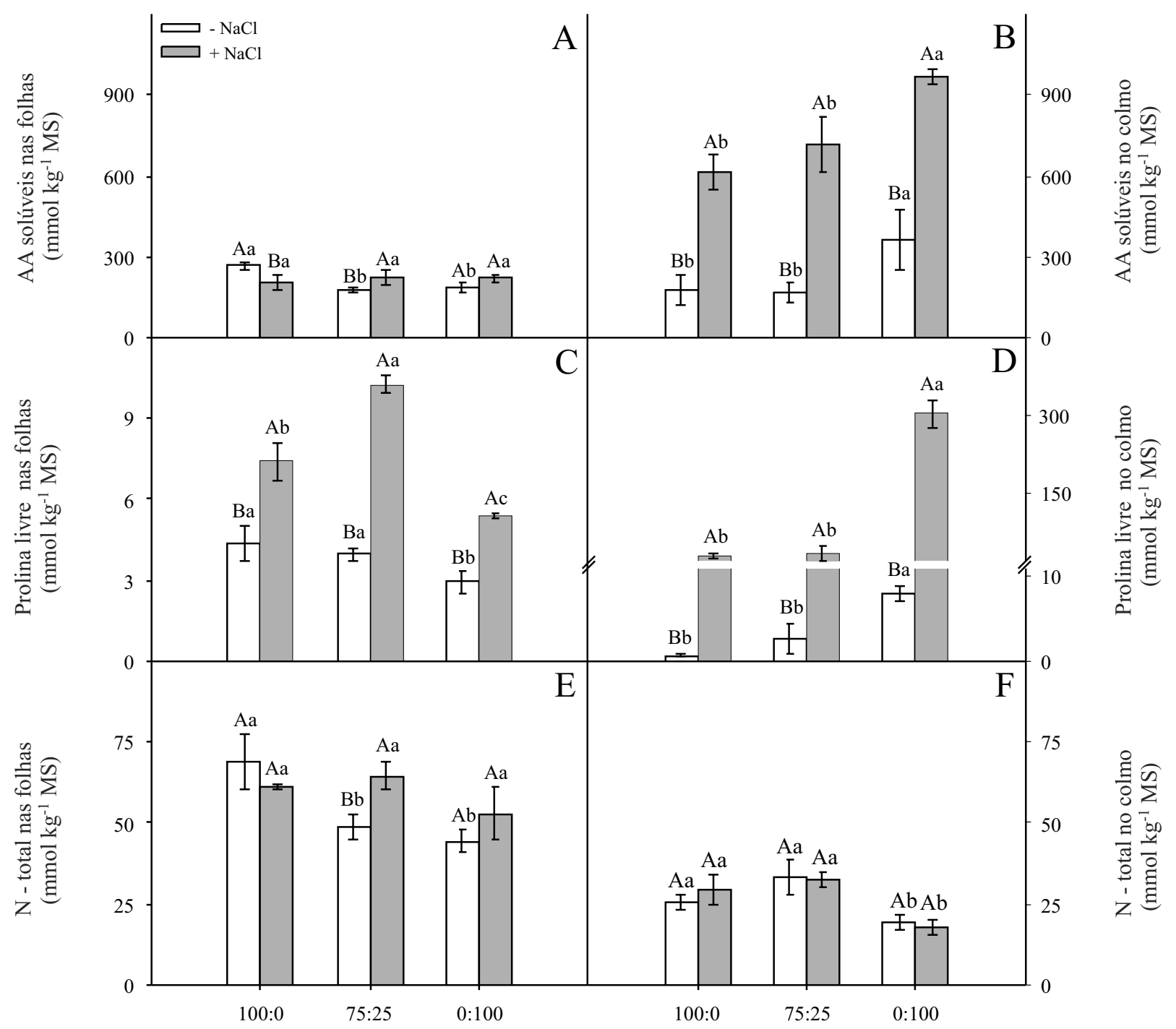

Tratamentos

Tratamentos

Figura 2 - Concentração de aminoácidos solúveis, prolina livre e nitrogênio total nas folhas (A, C e E) e colmo (B, D e F) de plantas de sorgo submetidas a diferentes formas de nitrogênio e à salinidade. Letras maiúsculas iguais indicam que não houve diferença significativa entre os tratamentos $-\mathrm{NaCl}$ e $+\mathrm{NaCl}$ e letras minúsculas iguais indicam que não houve diferença significativa entre os tratamentos de suplemento de nitrogênio $(100: 0,75: 25$ e 0:100) $(\mathrm{P}<0,05)$ 
presença ou ausência de sal, Dluzniewska et al. (2007) encontraram um aumento na concentração de aminoácidos solúveis totais nas folhas de plantas crescidas com amônio, na presença de $\mathrm{NaCl}$. Estes autores afirmaram que o aumento de aminoácidos nessas condições foi atribuído à proteólise de proteínas nas folhas. Um decréscimo de proteínas solúveis também foi encontrado nas plantas tratadas com amônio e salinidade deste experimento (dados não mostrados).

O maior acúmulo de aminoácidos no colmo pode também ser atribuído ao aumento da concentração de prolina livre. A perda da turgescência pela célula parece ser o fato inicial que desencadeia uma seqüência complexa de eventos adaptativos e resulta no acúmulo de prolina, sob estresse hídrico ou salino, para promover a diminuição no potencial osmótico no tecido (MUNNS; TESTER, 2008).

O acúmulo de prolina está relacionado em grande parte com o efeito inibidor do sal sobre a assimilação fotossintética de $\mathrm{CO}_{2}$ e aumento do catabolismo proteico, que, por sua vez, induz aumento da reciclagem de glicina- $\mathrm{NH}_{3}$ da fotorrespiração (LIN et al., 2002).

O aumento de prolina livre e aminoácidos livres totais no tecido estão relacionados com a resposta da planta ao estresse osmótico (PARIDA; DAS, 2005), como forma de reduzir o potencial hídrico na planta para tornar possível a absorção de água (TAIZ; ZEIGER, 2008). Uma forte relação entre o acúmulo de prolina livre e tolerância ao estresse tem sido sugerido por Ashraf e Foolad (2007).

O maior conteúdo de nitrogênio nas folhas do tratamento 75:25 e $+\mathrm{NaCl}$ foi favorecido pela substituição parcial do $\mathrm{NO}_{3}^{-}$pelo $\mathrm{NH}_{4}^{+}$, assim como encontrado por Kant et al. (2007).

Analisando-se os dados referentes a carboidratos solúveis nas folhas - $\mathrm{NaCl}$ não se observou diferença significativa. Já nas tratadas com sal $(+\mathrm{NaCl})$, o conteúdo deste soluto aumentou nos tratamentos 100:0 e 0:100. No colmo a concentração de carboidratos solúveis totais aumentou no tratamento $0: 100$ e $-\mathrm{NaCl}$ cerca de $127 \%$ em relação ao 75:25 - NaCl. No tratamento salino não teve diferença significativa (FIG. 3A; 3B).

A concentração de sacarose nas folhas reduziu de acordo com o aumento na quantidade de amônio aplicado, com uma redução de 52\% do tratamento 100:0 para o tratamento $0: 100$, ambos sem adição de sal.
Avaliando as plantas que foram submetidas à salinidade, verificaram-se reduções na acumulação de sacarose de 52\%; 58\% e 39\% nos tratamentos 100:0; 75:25 e $0: 100$, respectivamente. No colmo, foram verificadas pequenas variações onde as plantas $-\mathrm{NaCl}$ submetidas à maior quantidade de amônio obtiveram menor quantidade de sacarose e as plantas 75:25 e $+\mathrm{NaCl}$ acumularam este dissacarídeo em quantidade superior a este mesmo tratamento, mas sem adição de $\mathrm{NaCl}$ (FIG. 3C; 3D). Com relação às determinações de carboidratos solúveis totais e sacarose, as interações entre a forma de suprimento de nitrogênio e a salinidade foram significativas tanto em folhas quanto no colmo.

Com relação ao amido, não houve variações significativas nas folhas, tanto para os tratamentos de suprimento de nitrogênio como para os de salinidade. No colmo, observou-se acúmulo de amido de acordo com o aumento do nível de amônio aplicado, verificando-se aumento de $50 \%$ das plantas do tratamento 0:100 em relação as plantas do tratamento 100:0 (FIG. 3E; 3F). As interações entre suprimentos de nitrogênio e salinidade foram significativas somente nas folhas.

O maior acúmulo de carboidratos solúveis totais nas plantas tratadas com $\mathrm{NaCl}$ pode ter sido devido a uma menor utilização deste soluto como sugerido por Lacerda et al. (2003) ou este acúmulo foi utilizado no ajustamento osmótico celular (LACERDA et al., 2001).

O aumento na concentração de compostos orgânicos solúveis no citoplasma de plantas cultivadas e submetidas a estresse salino tem sido considerado como um mecanismo utilizado, pelas plantas, para balancear os potenciais osmóticos, entre o citoplasma e o vacúolo, e evitar danos aos sistemas enzimáticos (MUNNS, 2002; MUNNS; TESTER, 2008), protegendo as estruturas e funções celulares, além de constituir fonte de energia metabólica (VADEZ; SHARM, 2008). Aminoácidos e carboidratos solúveis são considerados os principais solutos orgânicos para o ajustamento osmótico de plantas submetidas a estresse hídrico e salino (AZEVEDO-NETO et al., 2004; LACERDA et al., 2001).

Além desses solutos, alguns carboidratos solúveis (glicose, frutose, sacarose e frutanos) e amido também podem ser acumulados nessas condições (PARIDA et al., 2002). Neste trabalho a concentração de sacarose diminui com a presença de sal e esse resultado não corrobora com os resultados encontrados por outros autores, Kerepesi e Galiba (2000) e Khatkar e Kuhad (2000), que relatam o aumento deste açúcar na presença de salinidade. A diminuição de sacarose 


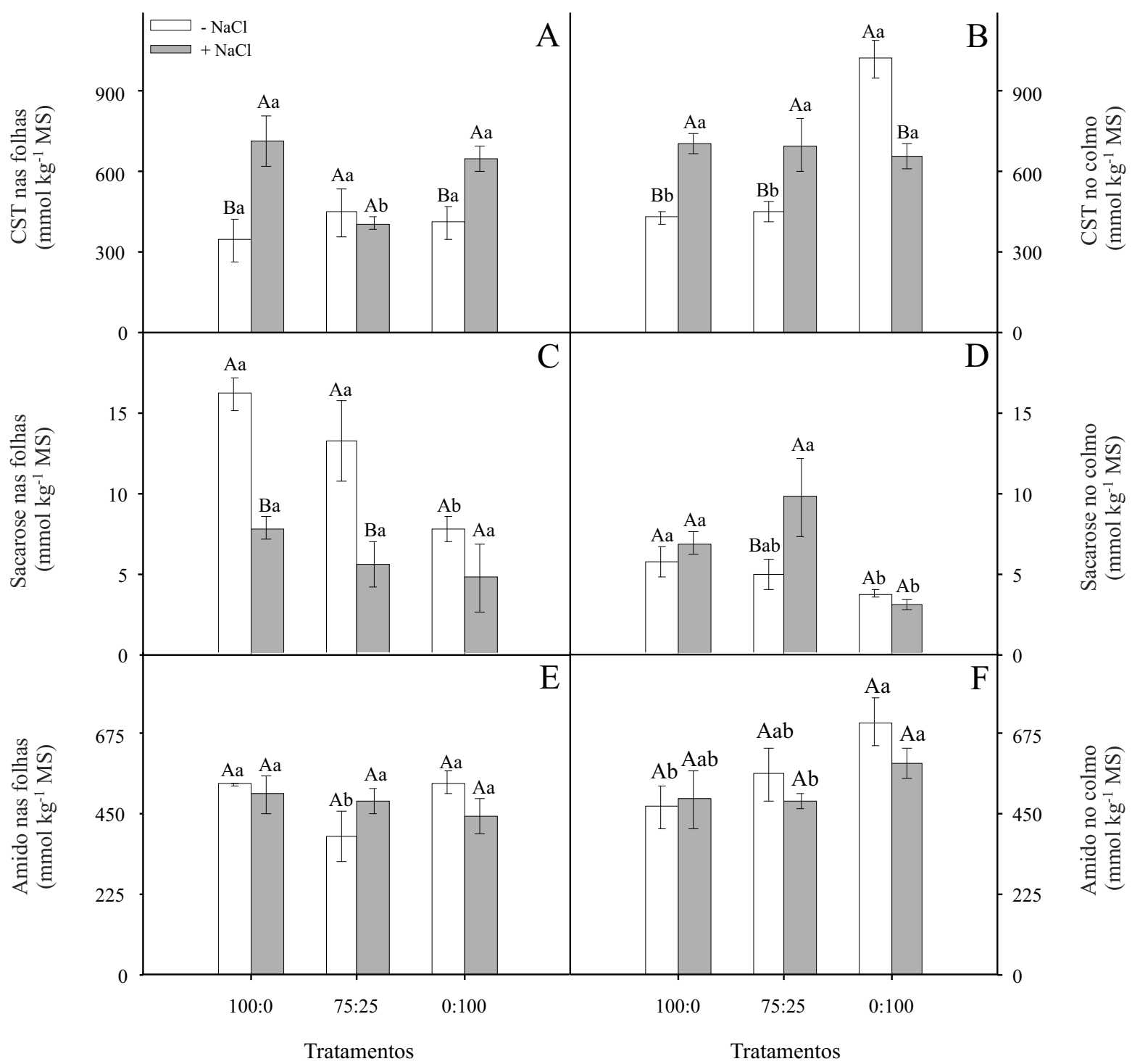

Figura 3 - Concentração de carboidratos solúveis totais, sacarose e amido nas folhas e colmo de plantas de sorgo submetidas a diferentes formas de nitrogênio e à salinidade. Letras maiúsculas iguais indicam que não houve diferença significativa entre os tratamentos $-\mathrm{NaCl}$ e $+\mathrm{NaCl}$ e letras minúsculas iguais indicam que não houve diferença significativa entre os tratamentos de suplemento de nitrogênio $(100: 0 ; 75: 25$ e 0:100) $(\mathrm{P}<0,05)$

pode ter levado a um aumento de glicose e frutose para serem utilizados no ajustamento osmótico.

\section{Conclusões}

1. Diante dos resultados, verificamos que as combinações de nitrato e amônio utilizadas afetam a acumulação de compostos nitrogenados e carboidratos, com presença ou ausência de $\mathrm{NaCl}$. Quando sob salinidade e amônio como única fonte de nitrogênio, observamos acúmulo de prolina, aminoácidos livres e amônio no colmo;
2. Desse modo, conclui-se que o sorgo forrageiro, sob estresse salino e excesso de amônio na sua fase inicial de desenvolvimento, tem acúmulo de compostos nitrogenados e carboidratos, sendo o colmo o órgão mais importante nesta acumulação.

\section{Referências}

ASHRAF, M.;FOOLAD, M. R. Roles of glycine betaine and proline in improving plant abiotic stress resistance. Environmental and Experimental Botany, v. 59, n. 2, p. 206-216, 2007. 
AZEVEDO-NETO, A. D. et al. Effects of salt stress on plant growth, stomatal response and solute accumulation of different maize genotypes. Brazilian Journal of Plant Physiology, v. 16, n. 1, p. 31-38, 2004.

BAETHGEN, W. E.; ALLEY, M. M. A manual colorimetric procedure for measuring ammonium nitrogen in soil and plant Kjeldahl digest. Community soil science and plant analysis, v. 20, n. 09/10, p. 961-969, 1989.

BATES, L. S. Rapid determination of free proline waterstress studies. Short Communication, Plant and Soil, v. 39, n. 01, p. 205-207, 1973.

BRITTO, D. T. et al. Futile transmembrane $\mathrm{NH}_{4}^{+}$cycling: A cellular hypothesis to explain ammonium toxicity in plants. Proceedings of the National Academy of Sciences, v. 98, n. 7, p. 4255-4258, 2001.

CATALDO, J. M.; HAROOM, M.; SCHRADER, L. E.; YOUNGS, V. L. Rapid colorimetric determination of nitrate in plant tissue by nitration of salicylic acid. Communications in Soil Science and Plant Analysis, v. 06, n. 1, p. 71-80, 1975.

DUBOIS, M. et al. Colorimetric method for determination of sugars and related substances. Analytical Chemistry, v. 28, n. 03, p. 350-356, 1956.

DEBOUBA, M. et al. $\mathrm{NaCl}$ stress effects on enzymes involved in nitrogen assimilation pathway in tomato Lycopersicon esculentum seedlings. Journal of Plant Physiology, v. 163, n. 12, p. 1247-1258, 2006.

DLUZNIEWSKA, P. et al. Nitrogen uptake and metabolism in Populus $\times$ canescens as affected by salinity. New Phytologist, v. 173, n. 02, p. 279-293, 2007.

KANT, S. et al. Partial substitution of $\mathrm{NO}_{3}^{-}$by $\mathrm{NH}_{4}^{+}$fertilization increases ammonium assimilating enzyme activities and reduces the deleterious effects of salinity on the growth of barley. Journal of Plant Physiology, v. 164, n. 03, p.303-311, 2007.

KHATKAR, D.; KUHAD, M. S. Short-term salinity induced changes in two wheat cultivars at different growth stages. Biologia Plantarum, v. 43, n. 04, p. 629-632, 2000.

KEREPESI, I.; GALIBA, G. Osmotic and salt stress-induced alteration in soluble carbohydrate content in wheat seedlings. Crop Science, v. 40, p. 482-487, 2000.

KRONZUCKER, H. J. et al. Nitrate-Ammonium Synergism in Rice. A Subcellular Flux Analysis. Plant Physiology, v. 119, n. 03, p. 1041-1045, 1999.

LACERDA, C. F. et al. A. Plant growth and solute accumulation and distribution in two sorghum genotypes, under $\mathrm{NaCl}$ stress. Revista Brasileira de Fisiologia Vegetal, v. 13, n. 03 , p. $270-284,2001$.

LACERDA, C. F. et al. Solute accumulation and distribution during shoot and leaf development in two sorghum genotypes under salt stress. Environmental and Experimental Botany, v. 49, n. 02, p. 107-120, 2003.

LANE, D. R.; BASSIRIRAD, H. Differential responses of tallgrass prairie species to nitrogen loading and varying ratios of $\mathrm{NO}_{3}^{-}$to $\mathrm{NH}_{4}^{+}$. Functional Plant Biology, v. 29, n. 10, p.1227-1235, 2002.
LIN, C. C.; HSU, Y. T.; Kao, C. H. The effect of $\mathrm{NaCl}$ on proline accumulation in rice leaves. Plant Growth Regulation, v. 36, n. 1, p. 275-285, 2002.

MCCREADY, R. M. et al. Determination of starch and amylase in vegetables. Analytical Chemistry, v. 22, n. 09, p. 1156-1158, 1950.

MUNNS, R. Comparative physiology of salt and water stress. Plant, Cell and Environment, v. 25, n. 02, p. 239-250, 2002.

MUNNS, R.; TESTER, M. Mechanisms of salinity tolerance. Annual Review of Plant Biology, v. 59, p. 651-681, 2008.

MELONI, D. A. et al. The effects of salt stress on growth, nitrate reduction and proline and glycinebetaine accumulation in Prosopis alba. Brazilian Journal Plant Physiology, v. 16, n. 01, p. 39-46, 2004.

OGAWA, K.; et al. Co-regulation of nitrate reductase and nitrite reductase in cultured spinach cells. Journal of Plant Physiology, v. 157, n.3, p. 299-306, 2000.

PARIDA, A.; DAS, A. B.; DAS, P. NaCl stress causes changes in photosynthetic pigments, proteins and other metabolic components in the leaves of a true mangrove, Bruguiera parviflora, in hydroponic cultures. Journal of Plant Biology, v. 45, n. 01, p. 28-36, 2002.

PARIDA, A. K.; DAS, A. B. Effects of $\mathrm{NaCl}$ stress on nitrogen and phosphorous metabolism in a true mangrove Bruguiera parviflora grown under hydroponic culture. Journal of Plant Physiology, v. 161, n. 08, p. 921-928, 2004.

PARIDA, A. K.; DAS, A. B. Salt tolerance and salinity effects on plants: a review. Ecotoxicology and Environmental Safety, v. 60, n. 03 , p. 324-349, 2005.

TAIZ, L.; ZEIGER, E. Plant physiology. Sunderland: Sinauer Associates, 2008. 819p.

VADEZ, P. B. M. V.; SHARM, K. K. Transgenic approaches for abiotic stress tolerance in plants: retrospect and prospects. Plant Cell Reports, v. 27, n. 3, p. 411-424, 2008.

VAN HANDEL, E. Direct microdetermination of sucrose. Analytical Biochemistry, v. 22, n. 02, p. 280-283, 1968.

WEATHERBURN, M. W. Phenol-hypochlorite reaction for determination of ammonia. Analytical Chemistry, v. 39, n. 08 , p. 971-974, 1967.

YEMM, E. W.; COCKING, E. F. The determination of amino acids with ninhydrin. Analyst, v. 80, n. 02, p. 209-213, 1955.

ZHAO, D. et al. Selection of optimum reflectance ratios for estimating leaf nitrogen and chlorophyll concentrations of fieldgrown cotton. Agronomy Journal, v. 97, n. 01, p. 89-98, 2005.

ZHOU, W. et al. Effect of salt stress on ammonium assimilation enzymes of the roots of rice (Oryza sativa) cultivars differing in salinity resistance. Acta Botanica Sinica, v. 46, n. 08, p. 921-927, 2004.

ZHOU, Y., et al. Effects of nitrogen form on growth, $\mathrm{CO}_{2}$ assimilation, chlorophyll fluorescence, and photosynthetic electron allocation in cucumber and rice plants. Journal of Zhejiang University-SCIENCE $B$ (Biomedicine and Biotechnology), v.12, n. 2, p. 126-134, 2011. 